(c) American Dairy Science Association, 2004.

\title{
Genetic Parameters for Days Open and Pregnancy Rates in US Holsteins Using Different Editing Criteria
}

\author{
S. Oseni, S. Tsuruta, I. Misztal, and R. Rekaya \\ Department of Animal and Dairy Science, \\ The University of Georgia, Athens 30602-2771
}

\begin{abstract}
The influence of various editing criteria for days open (DO) records on genetic parameter estimates of DO and pregnancy rates (PR) in US Holsteins was investigated. Data included first parity 305-d milk yield and DO records from 8 states: Georgia (GA), Florida (FL), North Carolina (NC), Texas (TX), Arizona (AZ), California (CA), New York (NY), and Wisconsin (WI). The pregnancy rate was computed as $1 /[(\mathrm{DO}-\mathrm{VWP}) / \mathrm{HI}+1)]$, where VWP was the approximate voluntary waiting period and HI was the heat interval set as $21 \mathrm{~d}$. The upper limit for PR was set to 1.0. A bivariate animal model for DO (or PR) and 305-d milk yield was fit separately for each state. The model included fixed effects of herd-year, month of calving, and age of cow, as well as random animal and residual effects. In separate analyses, maximum DO records were limited to 150 , 200, 250, 300, and $365 \mathrm{~d}$. Analyses for PR used values of 50, 80, and $120 \mathrm{~d}$ for the VWP. Genetic and residual variances for $\mathrm{DO}$ were strongly dependent on the upper limit; both variances were 8 times larger as the upper bound increased from 150 to $365 \mathrm{~d}$. Estimates of heritability for DO varied between 0.03 and 0.06 . There was a $30 \%$ increase in the heritability estimate as the upper limit increased from 150 to $250 \mathrm{~d}$ for FL and NC, and small or no increases for the other states. The increase of the upper limit from 250 to 365 d resulted in little change. The genetic correlation between milk and DO was the highest for FL (0.6) and the lowest for GA (0.12 to 0.23 ). For PR with VWP $=50$, the heritability was higher than the corresponding estimate for DO in GA, equal to that in $\mathrm{AZ}$, and lower in the remaining states. Heritabilities of PR also varied by the length of VWP; highest heritabilities were obtained at VWP $=50 \mathrm{~d}$ for GA and AZ; at VWP = $80 \mathrm{~d}$ for NY and WI; at VWP = $120 \mathrm{~d}$ for $\mathrm{FL}, \mathrm{NC}$, and CA. Increase of genetic variation for records of DO $<250 \mathrm{~d}$ was small. Days open and PR are strongly influenced by differences in management protocols among states.
\end{abstract}

Received April 13, 2004.

Accepted July 16, 2004.

Corresponding author: Shogo Tsuruta; e-mail: shogo@uga.edu.
(Key words: days open, pregnancy rate, voluntary waiting period, genetic parameters)

Abbreviation key: DO = days open, $\mathbf{P R}=$ pregnancy rate, $\mathbf{V A}=$ additive genetic variance, $\mathbf{V E}=$ residual variance, $\mathbf{V W P}=$ voluntary waiting period.

\section{INTRODUCTION}

Days open (DO) has been analyzed routinely in dairy cows (Thaller, 1997; Norman et al., 2002; VanRaden et al., 2003). However, there is no consensus among authors as to editing criteria for this trait. The USDA/ Animal Improvement Programs Laboratory uses an upper limit of $250 \mathrm{~d}$ (VanRaden et al., 2003). Others (Seykora and McDaniel, 1983; Hansen et al., 1983a; Hoeschele, 1991; Fuerst and Sölkner, 1994; Dematawewa and Berger, 1998; Abdallah and McDaniel, 2000; Oseni et al., 2003) have used various DO editing by data truncation (whereby DO records greater than a certain threshold are edited) or by setting upper limits (where DO records beyond a certain limit are set to that limit). Thresholds used in other studies are 150 , 250, 300, 305, 310, 365, 450, and $701 \mathrm{~d}$.

Several authors (Janson and Andreasson, 1981; Butler and Smith, 1989) have argued that interval traits like DO and calving interval are not good measures of cow fertility because of the large influence of management through preferential husbandry. The breeding of cows can be intentionally delayed due to high yield, bST use, embryo transfer, or seasonal factors (LunaDominguez et al., 2000; Rajala-Schultz and Frazer, 2003). Arbel et al. (2001) examined the profitability potentials in extended DO and calving interval in Israeli herds and presented evidence indicating that highproducing herds can be allowed a longer voluntary waiting period (VWP; $150 \mathrm{~d}$ for primiparous cows and 120 $\mathrm{d}$ for multiparous cows) without compromising profitability. Thus, the inclusion of records with long DO may give biased estimates of genetic parameters for DO and may introduce bias in sire evaluations for fertility (Seykora and McDaniel, 1983). However, elimination of such records may lead to the editing of data on infertile animals - the primary target group for genetic evalua- 
tions. A compromise used by USDA/Animal Improvement Programs Laboratory (VanRaden et al., 2003) involves setting limits, where DO over a certain age (or open cows) are assigned a limit or bound. Thus, large residual variance caused by prolonged DO records is restricted so that the proportion of total variance due to additive genetic variance is increased (Hansen et al., 1983a).

Management of reproduction may vary in different states of the United States. Norman et al. (2002) identified the VWP between calving and first breeding, use of bST, and designed reproductive programs as some key management factors that may impact genetic evaluations for DO. Oseni et al. (2003) have shown that parameters of $\mathrm{DO}$, such as mean and SD, varied by state and season of calving. In some cases, the distribution of DO was bimodal, indicating delayed breeding due to summer heat stress. If breeding is delayed due to hot weather, prolonged DO would not only be due to low fertility but also due to management, and heritability estimates of records with large DO limit will be lower. If breeding for productive cows is delayed, such management (environmental) intervention could possibly lead to lower heritability estimates.

Days open is largely effected by long DO records. In contrast, pregnancy rate (PR), which can be derived approximately as a function of DO, puts a large emphasis on short DO records. VanRaden (2003) noted that PR could be viewed as a sequence of 'yes' or 'no' (or binomial) variables within each 21 -d period. According to this author, instead of one record per lactation, a cow that becomes pregnant during the fourth period could be seen as having 4 observations denoted as [no, no, no, yes]. Equivalently, a PR record of 0.25 receives 4 times as much weight in the evaluation as another cow that conceives in the first $21 \mathrm{~d}$, with one observation denoted as [yes]. Using this weighted approach, this author reported that evaluations for PR were nearly identical to DO. The purpose of this paper was to examine the effect of different upper limits and length of the VWP on genetic parameters of DO and PR in selected US states. States included are those with high level of heat stress and at least moderate presence of dairying, and some selected major states in dairy production.

\section{MATERIALS AND METHODS}

Fertility data on first-parity calvings of Holstein cows for Georgia (GA), Florida (FL), North Carolina (NC), Texas (TX), Arizona (AZ), California (CA), New York (NY), and Wisconsin (WI) were extracted from the master file from USDA/AIPL. These datasets covered all states of the US over a 6-yr period from 1997 to 2002. Data editing included setting records greater than 21 $\mathrm{d}$ and less than $50 \mathrm{~d}$ to $50 \mathrm{~d}$. Subsets of the data for each state were created by setting upper limits to DO at 150, 200, 250, 300, and $365 \mathrm{~d}$. By setting upper limits, records greater than a specific threshold were set to that threshold. California, Wisconsin, and New York had large datasets (over 1 million records each). For these 3 states, first parity records of the original datasets were randomly sampled by herd to reduce computing. Pregnancy rate was defined as follows:

$\mathrm{PR}=1 /[(\mathrm{DO}-\mathrm{VWP}) / \mathrm{HI}+1]$, where VWP $=$ approximate VWP (set at $50 \mathrm{~d}$ ) and $\mathrm{HI}=$ heat interval (set at $21 \mathrm{~d}$ ). Subsets of the data for each state were created at different VWP of 50, 80, and $120 \mathrm{~d}$.

\section{Models}

A bivariate animal model, with DO (or PR) and 305d milk yield was fit as follows:

$$
y_{i j k l m t}=h y_{i t}+m_{j} c_{j t}+a_{e} e_{k t}+a_{l t}+e_{i j k l m t},
$$

where $y_{i j k l m t}$ is DO or PR $(t=1)$ and first-lactation 305$\mathrm{d}$ milk yield $(\mathrm{t}=2)$ for animal $\mathrm{l}$ in the age class $\mathrm{k}(\mathrm{k}=$

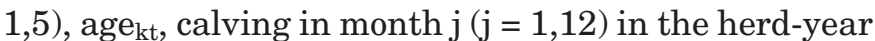
$\left(h_{\mathrm{it}}\right)$ class $\mathrm{i} ; \mathrm{moc}_{\mathrm{jt}}=$ fixed effect of the month of calving $\mathrm{j} ; \mathrm{a}_{\mathrm{lt}}=$ random effect of the animal $\mathrm{l}$; and $\mathrm{e}_{\mathrm{ijklmt}}=$ random error associated with each observation. Animal and residual effects for both traits were assumed correlated. (Co)variance components were estimated using the Average Information REML procedure via AIREMLF90 (Misztal et al., 2002).

\section{RESULTS AND DISCUSSION}

\section{Phenotypic Means and Standard Deviations}

Table 1 contains the means and standard deviations for DO across 5 upper bounds. Means for DO increased by 25 to $50 \%$ as DO upper limit increased from 150 to $365 \mathrm{~d}$. Mean DO for FL was the highest across all the thresholds, followed by the mean for GA; means for TX and $\mathrm{NC}$ were intermediate and higher than the means for AZ, CA, NY, and WI, which were all similar. These rankings were mostly maintained across all thresholds. Mean DO of 153 and 169 d reported for IA (Dematawewa and Berger, 1998) and NC (Abdallah and McDaniel, 2000) herds respectively, fall within the range of mean DO at the 300-d limit in the current study. Also, across most upper bounds, standard deviations were smaller for WI, NY, and AZ data, suggesting that herd management for DO may be more consistent for herds in these states than in the other states. 
Table 1. Means and standard deviations of days open (DO) across different upper bounds (150, 200, 250, 300 , and $365 \mathrm{~d}$ ).

\begin{tabular}{|c|c|c|c|c|c|c|c|c|c|c|c|}
\hline \multirow[b]{2}{*}{ State } & \multirow[b]{2}{*}{$\mathrm{n}$} & \multicolumn{2}{|c|}{ DO150 } & \multicolumn{2}{|c|}{ DO200 } & \multicolumn{2}{|c|}{ DO250 } & \multicolumn{2}{|c|}{ DO300 } & \multicolumn{2}{|c|}{ DO365 } \\
\hline & & Mean & SD & Mean & SD & Mean & SD & Mean & SD & Mean & SD \\
\hline Georgia & 21,484 & 120 & 36 & 139 & 55 & 154 & 72 & 164 & 87 & 172 & 101 \\
\hline Florida & 20,528 & 123 & 34 & 145 & 54 & 161 & 72 & 173 & 88 & 183 & 104 \\
\hline North Carolina & 28,240 & 119 & 36 & 138 & 55 & 151 & 71 & 159 & 84 & 166 & 96 \\
\hline Texas & 70,158 & 117 & 37 & 135 & 56 & 149 & 73 & 158 & 87 & 166 & 100 \\
\hline California & 49,056 & 108 & 38 & 121 & 55 & 130 & 68 & 135 & 79 & 140 & 89 \\
\hline Wisconsin & 42,757 & 109 & 37 & 121 & 52 & 128 & 64 & 132 & 73 & 135 & 80 \\
\hline Arizona & 49,548 & 112 & 35 & 125 & 51 & 132 & 64 & 137 & 73 & 140 & 81 \\
\hline New York & 36,307 & 111 & 36 & 124 & 53 & 132 & 65 & 136 & 74 & 139 & 82 \\
\hline
\end{tabular}

\section{Variance Components and Heritability}

Figures 1 and 2 present the residual variance $(\mathbf{V E})$ at different upper bounds for $\mathrm{DO}$ and $\mathrm{PR}$ respectively. Residual variances for DO showed a steady increase (4 to 8 times) from the 150- to 365-d upper limit. At the 150 -d threshold, estimates of VE ranged from 982 for FL to 1289 for CA. Hoeschele (1991) reported a VE of 1041 for DO at the 150-d bound for a combined data set from several states in Southeastern US. Similarly, residual variance of 6265 , reported by Dematawewa and Berger (1998), for upper limit DO of $305 \mathrm{~d}$ falls within the range of VE for the 300-d upper limit in the current study. It is, however, lower than the estimate of 9981 reported by Campos et al. (1994) for FL herds. Among states, there were small differences for residual variances at the 150 - and $200-d$ bounds. However, larger differences are seen at higher DO thresholds $(\geq 250 \mathrm{~d})$, with higher estimates for the southeastern

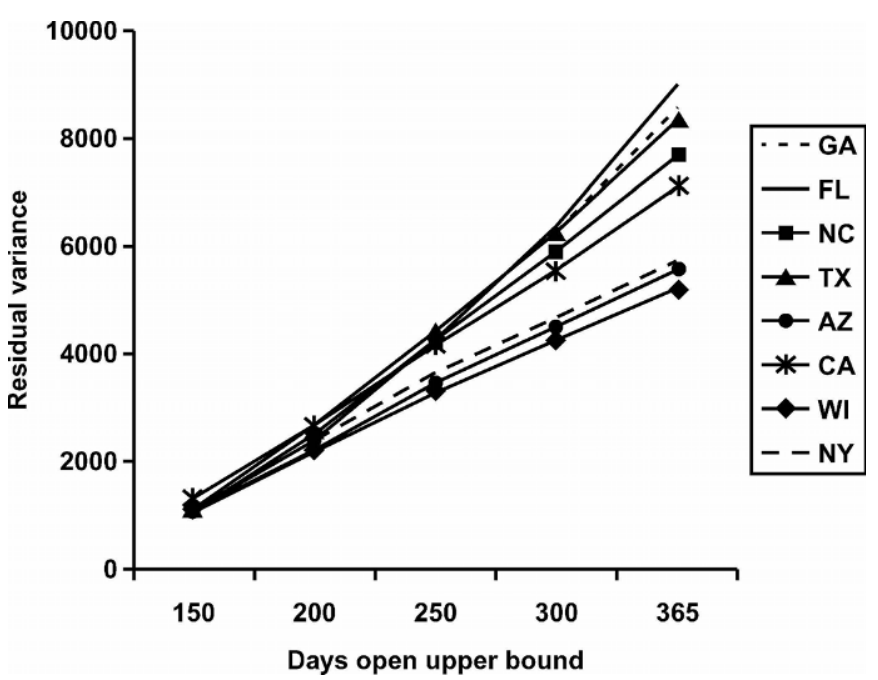

Figure 1. Residual variances for days open across different upper bounds in Georgia (GA), Florida (FL), North Carolina (NC), Texas (TX), California (CA), Wisconsin (WI), Arizona (AZ), and New York (NY). states - GA, NC, FL, and TX. In contrast to DO, VE for PR (Figure 2) showed very slight differences (12 to $22 \%$ ) across thresholds, indicating that PR is less affected by different limits when compared with DO. The relative stability of $P R$ across DO thresholds makes it a trait of choice for genetic evaluations for fertility.

Additive genetic variance (VA) for DO (Figure 3) increased up to 8 times between the lowest and highest DO upper bounds. Patterns of fluctuations across different upper bounds were similar among states, except for FL. The range of VA at the 150-d threshold was 34 (NC) to 67 (CA), higher than the estimates of 22.6 reported by Hoeschele (1991) for genetic variance for DO at the 150-d upper bound using a sire model. However, the estimate of 277.5 reported by Dematawewa and Berger (1998; IA data) was within the ranges of VA in the current study, whereas the estimate of 549 (Campos et al., 1994; FL data) was outside the ranges at the 300d bound. For PR, (Figure 4), smaller changes in VA

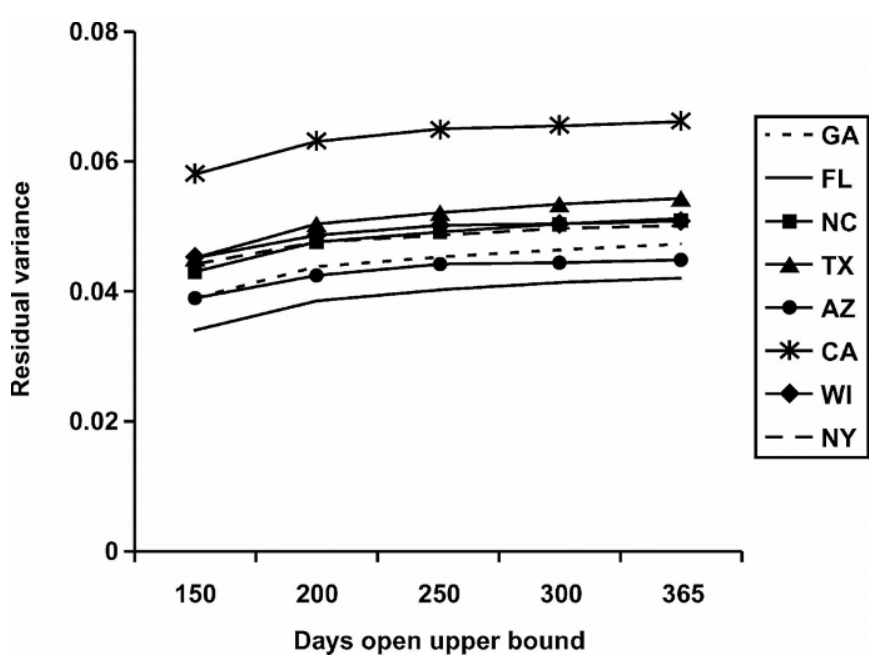

Figure 2. Residual variances for pregnancy rate across different days open bounds in Georgia (GA), Florida (FL), North Carolina (NC), Texas (TX), California (CA), Wisconsin (WI), Arizona (AZ), and New York (NY). 


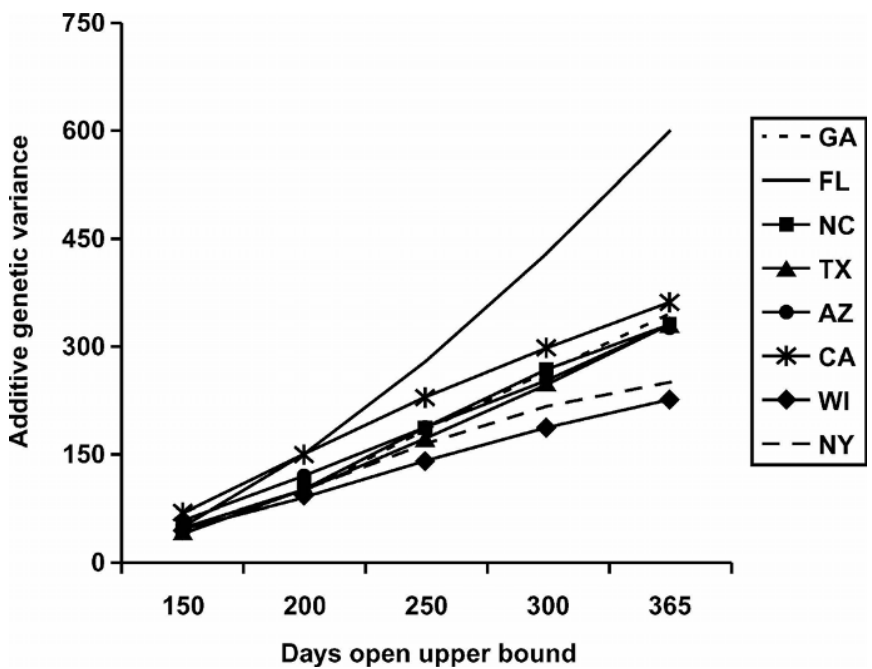

Figure 3. Additive genetic variances for days open across different upper bounds in Georgia (GA), Florida (FL), North Carolina (NC), Texas (TX), California (CA), Wisconsin (WI), Arizona (AZ), and New York (NY).

(approximately 40\%) across DO thresholds were observed, a trend similar to the VE patterns for PR. Smaller variation in $\mathrm{PR}$ is due to low weight for records with long DO.

Heritability estimates for DO (Figure 5) ranged between 0.03 and 0.063 , in close agreement with the estimates of 0.02 to 0.06 in the literature for $\mathrm{DO}$ and other interval traits (Hansen et al., 1983a,b; Hayes et al., 1992; Marti and Funk, 1994; Van Arendonk et al., 1989;

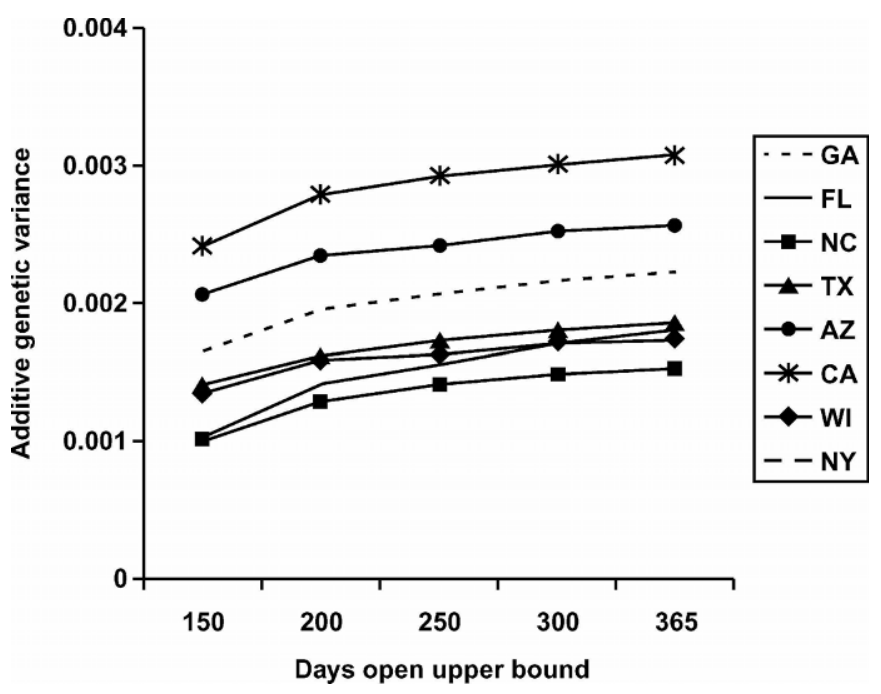

Figure 4. Additive genetic variances for pregnancy rate across different days open bounds in Georgia (GA), Florida (FL), North Carolina (NC), Texas (TX), California (CA), Wisconsin (WI), Arizona (AZ), and New York (NY).

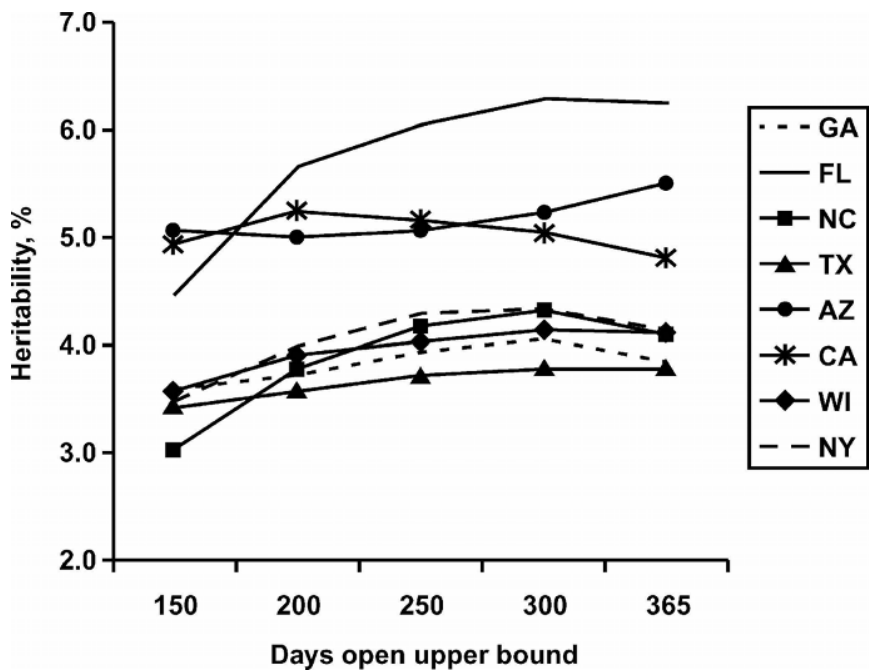

Figure 5. Heritability estimates for days open across different upper bounds in Georgia (GA), Florida (FL), North Carolina (NC), Texas (TX), California (CA), Wisconsin (WI), Arizona (AZ), and New York (NY).

Poso and Mantysaari, 1996; Dematawewa and Berger, 1998). For most states, estimates of heritability at thresholds $\geq 250 \mathrm{~d}$ were identical and differed from heritability estimates at the 200-d or less threshold. This may imply that there is higher genetic variability at higher DO thresholds ( $\geq 250 \mathrm{~d}$ ). Conversely, this finding may indicate genetic uniformity at lower DO thresholds ( $\leq 200 \mathrm{~d})$. Hoeschele (1991), using a Sire model, reported no difference in heritability estimates for DO at the 305and 150-d thresholds, whereas VanRaden and Tooker (2003) found higher heritability estimates as the upper limit decreased from 305 to $150 \mathrm{~d}$. Perhaps differences in model assumptions could explain these disparities in reports.

Heritability estimates for PR at VWP $=50 \mathrm{~d}$ (Figure 6) were lower than the corresponding estimates for DO for most states (FL, NC, WI, TX, CA, NY), which may imply that the genetic control of long DO may be more heritable. A similar decrease in heritability estimates for PR when compared with DO was also reported by VanRaden and Tooker (2003). Days open as a fertility measure puts more emphasis on later records, in contrast to PR, which puts more weight on earlier records. The relative stability of the heritability estimates for PR across DO thresholds in addition to the fact that cows can be evaluated every 21-d period for PR make this trait a favorable choice for national genetic evaluation. Further, PR de-emphasizes long DO records, which could have been generated under questionable assumptions (e.g., intentional delay by the farmer, seasonal factors). The calculation of PR assumed VWP of $50 \mathrm{~d}$. In reality, VWP varies across herds and has been 


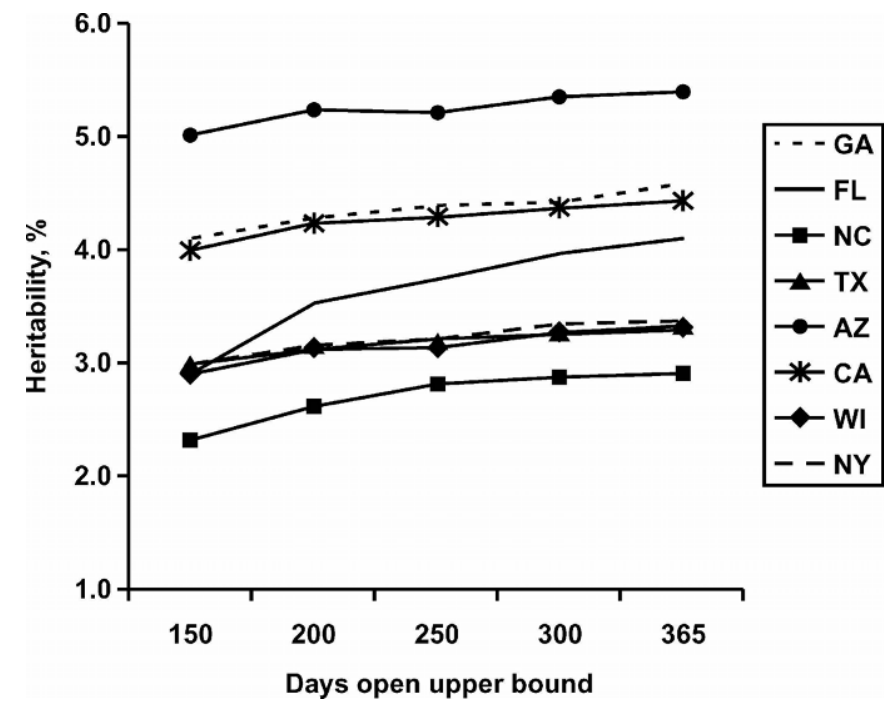

Figure 6. Heritability estimates for pregnancy rates across different days open upper bounds in Georgia (GA), Florida (FL), North Carolina (NC), Texas (TX), California (CA), Wisconsin (WI), Arizona (AZ), and New York (NY).

identified by Norman et al. (2002) as one of the management factors affecting genetic parameters for DO. No information on the length of the VWP was available. Voluntary waiting period can be partially ascertained through analyses of within-farm records. However, the length of the VWP may vary for cow groups within farm due to production level, cull prices, season, etc. (B. Cassell and R. Pearson, 2003, personal communication).

Table 2 shows estimates of heritability at different (assumed) VWP of 50, 80, and $120 \mathrm{~d}$. For GA and AZ, the highest heritability was for VWP $=50 \mathrm{~d}$ and it was higher than the estimate for DO. In states with seasonal heat stress, the length of VWP during the cooler season may be short, to maximize chances that cows are successfully bred before the onset of seasonal heat stress. Higher heritability for PR than for DO suggests that important genetic differences for some states occurred in animals with low rather than high DO. For CA and FL, the highest heritability was at VWP $=120 \mathrm{~d}$. This suggests low genetic variability at $\mathrm{DO}<120 \mathrm{~d}$, which could probably be ignored. For these states, also, heritability for DO was always higher than for PR. This suggests that records with large $\mathrm{DO}$, which received minimal weight under PR, contained substantial genetic information. High VWP could be due to greater profitability at higher VWP when fertility is adequate (CA), or due to low conception rates at short VWP, particularly under constant heat stress (FL). These varied trends of PR with changing VWP agree with the report of Norman et al. (2002) that the length of the VWP was a management factor in the genetic evaluation of dairy cattle for fertility. Differences between states in the genetic parameters for PR could also be due to differences in heat detection (Dransfield et al., 1998; Washburn et al., 2002). These authors noted that in many herds, $<50 \%$ heats are detected. Factors omitted in this study were differences between herds in reproductive management protocols (e.g., estrous synchronization, timed AI). Goodling et al. (2003) showed that heritability estimates for days to first breeding were higher for synchronized cows than for nonsynchronized cows (8.0 vs. $5.3 \%$, respectively).

In most states, heritability estimates for DO were higher at thresholds $<250 \mathrm{~d}$, whereas differences in heritability estimates were minimal or nonexistent for thresholds beyond $250 \mathrm{~d}$. Also, for PR, highest heritability was at VWP $=120 \mathrm{~d}$ for some states. Consequently, records of DO can be limited in the range of 120 to $250 \mathrm{~d}$ or perhaps even 120 to $200 \mathrm{~d}$, without lowering heritability estimates. If lower and upper limits or thresholds can be set to most DO records, then this trait will be close to binary, where the first category is "pregnant before the lower limit" and the second is "not pregnant" by the upper limit.

\section{Genetic and Phenotypic Correlations Between DO and Milk}

Estimates of genetic correlations between DO and 305-d milk yield are shown in Figure 7. Estimates were

Table 2. Heritability estimates (\%) for pregnancy rates at 50, 80, and $120 \mathrm{~d}$ of voluntary waiting periods (VWP) using different upper bounds (150, 250, and $365 \mathrm{~d})$ of days open (DO).

\begin{tabular}{|c|c|c|c|c|c|c|c|c|c|}
\hline \multirow[b]{2}{*}{ State } & \multicolumn{3}{|c|}{ DO150 } & \multicolumn{3}{|c|}{ DO250 } & \multicolumn{3}{|c|}{ DO365 } \\
\hline & VWP50 & VWP80 & VWP120 & VWP50 & VWP80 & VWP120 & VWP50 & VWP80 & VWP120 \\
\hline Georgia & 4.1 & 3.2 & 2.7 & 4.4 & 3.5 & 2.9 & 4.5 & 3.6 & 3.0 \\
\hline Florida & 2.9 & 3.5 & 4.8 & 3.7 & 4.3 & 5.6 & 4.1 & 4.6 & 5.7 \\
\hline North Carolina & 2.3 & 2.5 & 2.6 & 2.8 & 3.0 & 3.3 & 2.9 & 3.1 & 3.5 \\
\hline Texas & 3.0 & 3.1 & 3.0 & 3.2 & 3.3 & 3.2 & 3.3 & 3.4 & 3.3 \\
\hline California & 4.0 & 4.2 & 4.8 & 4.3 & 4.5 & 5.0 & 4.4 & 4.5 & 5.0 \\
\hline Wisconsin & 2.9 & 3.3 & 2.5 & 3.1 & 3.3 & 3.0 & 3.3 & 3.4 & 3.1 \\
\hline Arizona & 5.0 & 4.7 & 3.8 & 5.2 & 5.0 & 4.2 & 5.4 & 5.0 & 4.3 \\
\hline New York & 2.9 & 3.3 & 2.7 & 3.2 & 3.6 & 3.2 & 3.4 & 3.7 & 3.3 \\
\hline
\end{tabular}




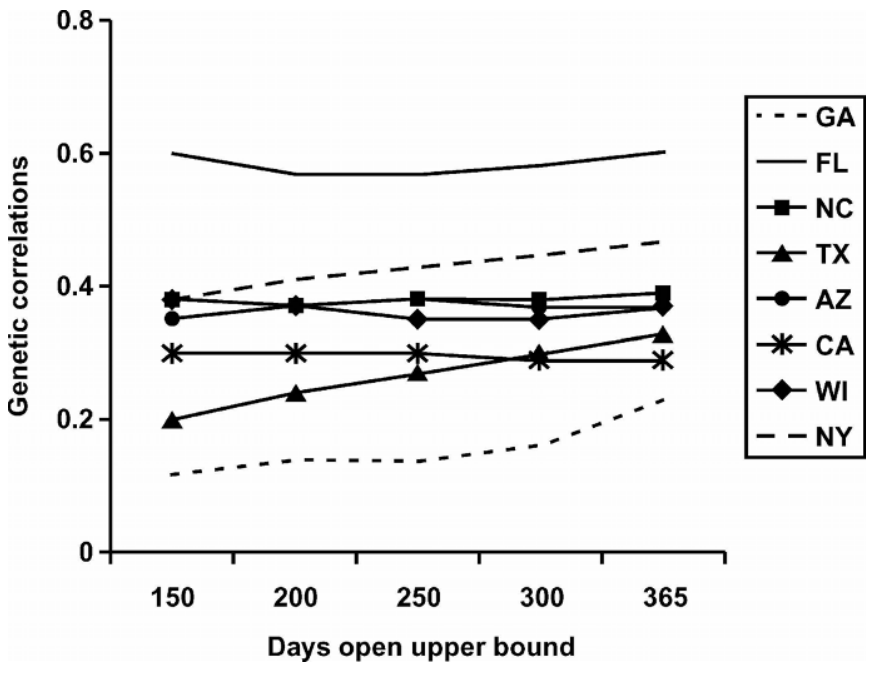

Figure 7. Genetic correlations between 305-d milk yield and days open across different days open upper bounds in Georgia (GA), Florida (FL), North Carolina (NC), Texas (TX), California (CA), Wisconsin (WI), Arizona (AZ), and New York (NY).

relatively constant across DO upper limits within states, indicating that genetic correlations between $\mathrm{DO}$ and 305-d milk were unaffected by DO thresholds. Similar trends were observed for the genetic correlations between PR and 305-d milk yield (data not shown). However, most of the estimates were moderately antagonistic for most states and highly antagonistic for FL, in agreement with reports in the literature (Hansen et al., 1983a; Short et al., 1990; Campos et al., 1994). These estimates may imply preferential husbandry in many states, suggesting that the production level could play a major role in determining when to rebreed cows. Philipsson (1981) described such genetic correlations as 'forced' because they may have resulted from the intentional delay of some cows based on the level of milk yield. Alternatively, such moderate genetic correlations may indicate true genetic antagonisms between $\mathrm{DO}$ and milk yield - a phenomenon whereby a cow's energy resources are channeled toward milk production, leading to the suppression of reproduction functions, in agreement with several studies (Seykora and McDaniel, 1983; Hermas et al., 1987; Pryce and Veerkamp, 2001).

Estimates of phenotypic correlations between DO and 305-d milk yield (and PR vs. 305-d milk) at different DO thresholds were generally low $(\leq 0.13$ for DO and $\geq-0.14$ for PR) and relatively constant across all DO upper bounds within states (estimates not shown). Reports by several authors (Hansen et al., 1983a, Van Arendonk et al., 1989; VanRaden et al., 2003) also indicated low phenotypic correlations between DO and milk yield. Genetic correlations were, in general, higher than the corresponding phenotypic correlations, as found in other reports (Hansen et al., 1983a; Hoekstra et al., 1994; Pryce et al., 1997).

\section{CONCLUSIONS}

Heritability estimates for DO were higher or identical at DO thresholds $\geq 250 \mathrm{~d}$ when compared with lower thresholds, indicating greater genetic variability for long DO records. Estimates of variance components and heritability were more stable for PR across all thresholds when compared with DO. Heritability estimates for PR depended strongly on the assumed length of the VWP. The increase in genetic variation in DO with upper bounds $\geq 250 \mathrm{~d}$ was minimal, and records of DO could be limited to $250 \mathrm{~d}$ with little or no effect on the estimates of genetic parameters. Genetic correlations between DO (or PR) and 305-d milk yield were moderately antagonistic. Days open and PR can be analyzed more accurately when information on management of fertility such as the actual length of the VWP, service period, estrous synchronization, and bST are available.

\section{ACKNOWLEDGMENTS}

The meticulous efforts of the 2 anonymous reviewers are appreciated.

\section{REFERENCES}

Abdallah, J. M., and B. T. McDaniel. 2000. Genetic parameters and trends of milk, fat, days open and body weight after calving in North Carolina experimental herds. J. Dairy Sci. 83:1364-1370.

Arbel, R., Y. Bigun, E. Ezra, H. Sturman, and D. Hojman. 2001. The effect of extended calving intervals in high lactating cows on milk production and profitability. J. Dairy Sci. 84:600-608.

Butler, W. R., and R. D. Smith. 1989. Interrelationships between energy balance and post partum reproductive function in dairy cattle. J. Dairy Sci. 72:767-783.

Campos, M. S., C. J. Wilcox, C. M. Becerril, and A. Diz. 1994. Genetic parameters for yield and reproductive traits of Holstein and Jersey cattle in Florida. J. Dairy Sci. 77:867-873.

Dematawewa, C. M., and P. J. Berger. 1998. Genetic and phenotypic parameters for 305-d yield, fertility and survival in Holsteins. J. Dairy Sci. 81:2700-2709.

Dransfield, M. B. G., R. L. Nebel, R. E. Pearson, and L. D. Warnick. 1998. Timing of insemination for dairy cows identified in estrus by a radiotelemetric estrus detection system. J. Dairy Sci. 81:1874-1882.

Fuerst, C., and J. Sölkner. 1994. Additive and non-additive genetic variances for milk yield, fertility, lifetime performance traits of dairy cattle. J. Dairy Sci. 77:1114-1125.

Goodling, R. C., G. E. Shook, K. A. Weigel, N. R. Zwald, and R. D. Welper. 2003. Effects of synchronization protocols on the genetic parameters of reproductive traits in dairy cattle. J. Dairy Sci. 86 (Suppl. 1):129. (Abstr.).

Hansen, L. B., A. E. Freeman, and P. J. Berger. 1983a. Variances, repeatabilities and age adjustments of yield and fertility in dairy cattle. J. Dairy Sci. 66:281-292.

Hansen, L. B., A. E. Freeman, and P. J. Berger. 1983b. Yield and fertility relationships in dairy cattle. J. Dairy Sci. 66:293-305. 
Hayes, J. F., I. Cue, and H. G. Monardes. 1992. Estimates of repeatability of reproductive measures in Canadian Holsteins. J. Dairy Sci. 75:1701-1706.

Hermas, S. A., C. W. Young, and J. W. Rust. 1987. Genetic relationships and additive genetic variance of productive and reproductive traits in Guernsey dairy cattle. J. Dairy Sci. 70:1252-1257.

Hoekstra, J., A. W. van der Lugt, J. H. J. van der Werf, and W. Ouweltjes. 1994. Genetic and phenotypic parameters for milk production and fertility traits in upgraded dairy cattle. Livest. Prod. Sci. 40:225-232.

Hoeschele, I. 1991. Additive and non-additive genetic variances in female fertility of Holsteins. J. Dairy Sci. 74:1743-1752.

Janson, L., and B. Andreasson. 1981. Studies on fertility traits in Swedish cattle. IV. Genetic and phenotypic correlations between milk yield and fertility. Acta Agric. Scand. 31:313-322.

Luna-Dominguez, J. E., R. M. Enns, D. V. Armstrong, and R. L. Ax. 2000. Reproductive performance of Holstein cows receiving somatotropin. J. Dairy Sci. 83:1451-1455.

Marti, C. F., and D. A. Funk. 1994. Relationship between production and days open at different levels of herd production. J. Dairy Sci. $77: 1682-1690$

Misztal, I., S. Tsuruta, T. Strable, B. Auvray, T. Druet, and D. Lee. 2002. BLUPF90 and related programs (BGF90). Proc. 7th WCGALP, Montpellier, France. CD-ROM Communication 28:07.

Norman, H. D., R. H. Miller, P. M. VanRaden, and J. R. Wright. 2002. Genetic relationships among fertility traits of Holsteins and Jerseys. J. Dairy Sci. 85 (Suppl. 1):89 (Abstr.)

Oseni, S. O., I. Misztal, S. Tsuruta, and R. Rekaya. 2003. Seasonality of days open in US Holsteins. J. Dairy Sci. 86:3718-3725.

Philipsson, J. 1981. Genetic aspects of female fertility in dairy cattle. Livest. Prod. Sci. 8:307-319.
Pryce, J. E., and R. F. Veerkamp. 2001. The incorporation of fertility indices in genetic improvement programs. Pages 237-249 in Fertility in the High-Yielding Dairy Cow. Br. Soc. Anim. Sci. Occ. Pub. No. 26, Vol.1: Galway, Ireland.

Rajala-Schultz, P. J., and G. S. Frazer. 2003. Reproductive performance in Ohio dairy herds in the 1990s. Anim. Reprod. Sci 76:127-142. Seykora, A. J., and B. T. McDaniel. 1983. Heritabilities and correlations of lactation yields and fertility for Holsteins. J. Dairy Sci. 66:1486-1493.

Short, T. H., R. W. Blake, R. L. Quaas, and L. D. Van Vleck. 1990. Heterogeneous within- herd variance 2. Genetic relationships between milk yield and calving interval in grade cows Holstein cows. J. Dairy Sci. 73:3321-3329.

Thaller, G. 1997. Genetic and breeding for fertility. InterBull Bull. 18:55-61.

Van Arendonk, J. A. M., R. Hovenier, and W. de Boer. 1989. Phenotypic and genetic association between fertility and production in dairy cows. Livest. Prod. Sci. 21:1-12.

VanRaden, P. M. 2003. Longevity and fertility trait definitions compared in theory and simulation. InterBull Bull. 30:40-43.

VanRaden, P. M., A. Sanders, M. Tooker, R. Miller, and D. Norman. 2003. Daughter pregnancy rate evaluation of cow fertility. Online. Available: $\quad$ http://aipl.arsusda.gov/reference/fertility/ DPR_rpt.htm \#DPR. Accessed June 1, 2003.

VanRaden, P. M., and M. Tooker. 2003. Definition of trait and comparison of models for the genetic evaluation of cow fertility. J. Dairy Sci. 86(Suppl. 1):131.(Abstr.)

Washburn, S. P., W. J. Silva, C. H. Brown, B. T. McDaniel, and A. J. McAllister. 2002. Trends in reproductive performance in Southeastern Holstein and Jersey DHI Herds. J. Dairy Sci. $85: 244-251$. 